\title{
Outcome after emergency surgery in patients with a free perforation caused by gastric cancer
}

\author{
HIRONORI TSUJIMOTO ${ }^{1}$, SHUICHI HIRAKI ${ }^{1}$, NAOKO SAKAMOTO ${ }^{1}$, YOSHIHISA YAGUCHI ${ }^{1}$, \\ TAKUYA HORIO $^{1}$, ISAO KUMANO ${ }^{1}$, TAKAYOSHI AKASE ${ }^{1}$, HIDEKAZU SUGASAWA ${ }^{1}$, \\ SATOSHI AIKO ${ }^{1}$, SATOSHI ONO ${ }^{2}$, TAKASHI ICHIKURA ${ }^{1}$ and HASE KAZUO ${ }^{1}$ \\ ${ }^{1}$ Department of Surgery and ${ }^{2}$ Division of Basic Traumatology, Research Institute, \\ National Defense Medical College, Tokorozawa 359-8513, Japan
}

Received August 26, 2009; Accepted October 13, 2009

DOI: $10.3892 /$ etm_00000032

\begin{abstract}
Perforation of gastric cancer is rare and it accounts for less than $1 \%$ of the incidences of an acute abdomen. In this study, we reviewed cases of benign or malignant gastric perforation in terms of the accuracy of diagnosis and investigated the clinical outcome after emergency surgery in patients with a free perforation caused by gastric cancer. On the basis of pathological examination, gastric cancer was diagnosed in 8 patients and benign ulcer perforation in 32 patients. The sensitivity, specificity and accuracy of intraoperative diagnosis by pathological examination were 50, 93.8 and $85 \%$, respectively. Except for age, there were no differences in the other demographic characteristics between patients with gastric cancer and benign ulcer perforation. The median survival time of patients with perforated gastric cancer was 195 days after surgery. Patients with gastric cancer perforation had a poorer overall survival rate than those who had T3 tumors without perforation. In addition, in patients with perforation, recurrence of peritoneum occurred more frequently. In conclusion, to improve the survival rate of patients with perforated gastric cancer and to improve the accuracy of intraoperative diagnosis, endoscopic examination and/or pathological examination of the frozen section should be performed, if possible. A balanced surgical strategy using laparoscopic local repair as the first-step of surgery, followed by radical open gastrectomy with lymphadenectomy may be considered.
\end{abstract}

\section{Introduction}

Perforation of gastric cancer is rare and it accounts for less than $1 \%$ of the incidences of an acute abdomen $(1,2)$. It is difficult to identify the cause of gastric perforation during

Correspondence to: Dr Hironori Tsujimoto, Department of Surgery, National Defense Medical College, 3-2 Namiki, Tokorozawa 359-8513, Japan

E-mail: tsujihi@ndmc.ac.jp

Key words: gastric cancer, perforation, prognosis, peritonitis emergency surgery, particularly when a frozen section is unavailable. Even if the frozen section shows malignant perforation, the surgeon should choose the optimal surgical strategy, i.e., either a gastrectomy with lymphadenectomy or local repair according to the severity of sepsis.

In this study, we reviewed cases of benign or malignant gastric perforation in terms of the accuracy of diagnosis and investigated the clinical outcome after emergency surgery for patients with gastric cancer who had a free perforation.

\section{Materials and methods}

Patients. Between 1992 and 2007, 40 patients with perforation caused by gastric ulcer or gastric cancer were admitted to the National Defense Medical College Hospital. In all cases, the presence of free perforation was confirmed by examination of chest X-ray films and/or computed tomography (CT) scans. Patients with perforation caused by endoscopic mucosal resection (EMR) or endoscopic submucosal resection (ESD) were excluded from this study. To compare the clinical outcomes in gastric cancer patients with and without a free perforation, 196 patients with gastric cancer who underwent gastrectomy between 1992 and 2007 and whose tumors were classified as T3 of tumor depth without any evidence of perforation were used as controls. Medical records were reviewed to obtain information regarding patient demographics, surgical procedure, postoperative morbidity and mortality, and longterm survival. The pathological findings in patients with gastric cancer were described on the basis of the Japanese Classification of Gastric Carcinoma (3). For 2 patients with gastric cancer perforation who had not undergone a gastrectomy, the clinical findings were described instead of the pathological findings.

Statistical analysis. The data were expressed as the mean \pm standard error of the mean (SEM). Statistical analyses were performed using either the Mann Whitney $U$ test or the Chi-square test, and multivariate analysis was performed using a Cox proportional hazards model. A p-value of $<0.05$ was considered statistically significant. All analyses were performed using the statistical software StatView version 5.0 (SAS Institute, Inc., Cary, NC, USA). 
Table I. Clinicopathological characteristics of patients with gastric perforation according to the cause of perforation.

\begin{tabular}{|c|c|c|c|}
\hline & Malignancy & Benign & P-value \\
\hline No. of patients & 8 & 32 & \\
\hline Age (years) & $65.6 \pm 4.8$ & $55.1 \pm 2.3$ & 0.04 \\
\hline Gender $(\mathrm{M} / \mathrm{F})$ & $3 / 5$ & $23 / 9$ & 0.07 \\
\hline \multicolumn{4}{|l|}{ Location of perforation } \\
\hline Upper third & $0 \quad(0.0 \%)$ & $6(18.9 \%)$ & \multirow{3}{*}{0.41} \\
\hline Middle third & $4(50.0 \%)$ & $13(40.6 \%)$ & \\
\hline Lower third & $4(50.0 \%)$ & $13(40.6 \%)$ & \\
\hline Co-morbidity (yes) & $2(25.0 \%)$ & $15(46.9 \%)$ & 0.25 \\
\hline Peptic ulcer & $1(12.5 \%)$ & $4(12.5 \%)$ & $>0.99$ \\
\hline Hypertension & $0 \quad(0.0 \%)$ & $5(15.6 \%)$ & 0.37 \\
\hline Diabetes & $1(12.5 \%)$ & $2(6.3 \%)$ & 0.55 \\
\hline Another malignancy & $0 \quad(0.0 \%)$ & $4(12.5 \%)$ & 0.29 \\
\hline Communication problem & $0 \quad(0.0 \%)$ & $5(15.6 \%)$ & 0.23 \\
\hline WBC (per $\mu \mathrm{l}$ ) on admission & $11,900 \pm 1,846$ & $12,552 \pm 1,412$ & 0.83 \\
\hline Postoperative hospital stay (days) & $18.7 \pm 3.5$ & $21.6 \pm 2.2$ & 0.56 \\
\hline Postoperative complication (yes) & $2(25.0 \%)$ & $12(37.5 \%)$ & 0.73 \\
\hline ARDS & $0 \quad(0.0 \%)$ & $5(15.6 \%)$ & \\
\hline Wound infection & $2(25.0 \%)$ & $6(18.9 \%)$ & \\
\hline Intraabdominal abscess & $0 \quad(0.0 \%)$ & $1(3.1 \%)$ & \\
\hline \multirow[t]{3}{*}{ Mortality at 30 days } & $2(25.0 \%)$ & $1 \quad(3.3 \%)$ & \multirow[t]{3}{*}{0.04} \\
\hline & Sepsis (POD16) & Sepsis (POD27) & \\
\hline & Rupture of AAA (POD5) & & \\
\hline
\end{tabular}

WBC, white blood cell counts; ARDS, acute respiratory dysfunction syndrome; AAA, abdominal aortic aneurysm; POD, postoperative day.

\section{Results}

The clinical and pathological diagnoses for the 40 patients with free gastric ulcer or cancer perforation are shown in Fig. 1. All patients were diagnosed by pathological examination of the resected specimen or biopsy specimen; none of them were diagnosed by examination of the frozen section obtained during surgery. By pathological examination, gastric cancer was diagnosed in 8 patients and benign ulcer perforation in 32 patients. The sensitivity, specificity and accuracy of intraoperative diagnosis by pathological examination were 50, 93.8 and $85 \%$, respectively. Patients with gastric ulcer perforation (19 patients, 59.3\%) underwent more frequent local repair such as omental patch repair and omentopexy than those with gastric cancer perforation (1 patient, 12.5\%). No surgical intervention was performed in the case of 2 patients: 1 patient with gastric cancer perforation had general metastases and refused surgery, and 1 patient with gastric ulcer perforation underwent conservative therapy. The patients with gastric cancer perforation were significantly older than those with gastric ulcer perforation (Table I). There was no significant difference between patients with gastric cancer and benign ulcer perforation with regard to gender, location of perforation, co-morbidity rate, white cell count on admission, duration of

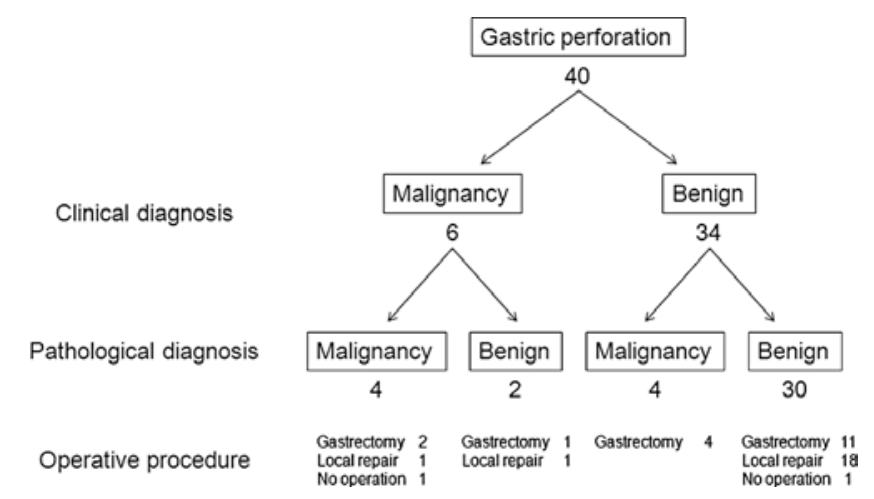

Figure 1. The clinical and pathological diagnoses and surgical procedures in patients with gastric perforation.

postoperative stay in the hospital and postoperative complications. Among the patients with gastric cancer perforation, 1 patient who underwent local repair died due to the development of sepsis on postoperative day (POD) 16; 1 patient who underwent subtotal gastrectomy died due to the rupture of an abdominal aortic aneurysm on POD 5; 1 patient with benign ulcer who underwent local repair died due to the development of sepsis on POD 27. 


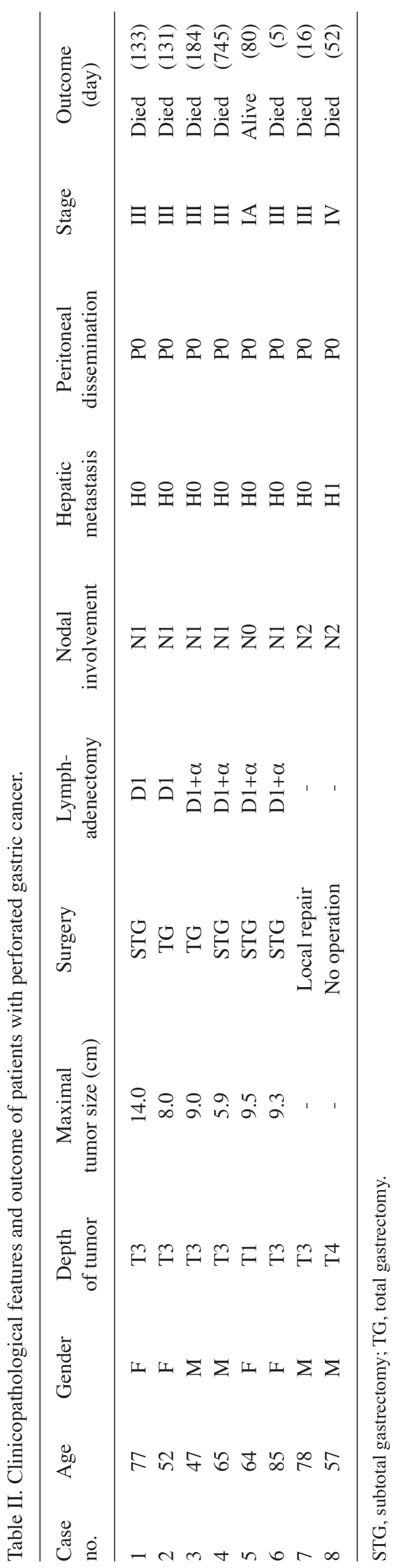

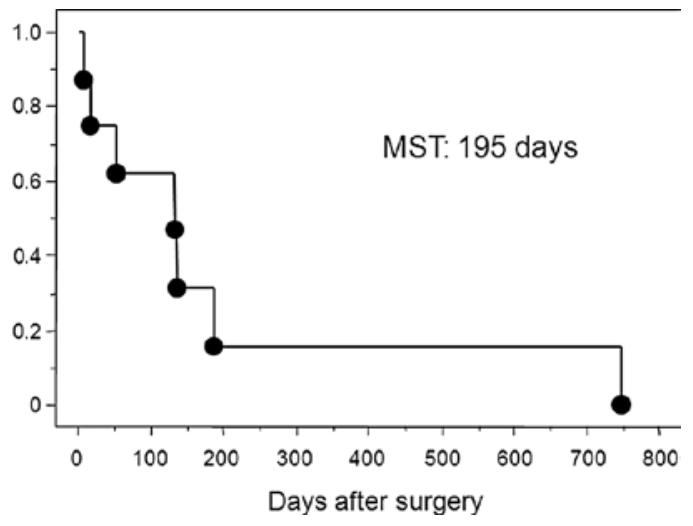

Figure 2. Overall survival rate in patients with free perforation due to gastric cancer. Median survival time (MST) is inserted.

The clinicopathological features of 8 patients with gastric cancer who had a free perforation are listed in Table II. During the investigation period, 1,081 gastrectomies were performed in our hospital, and the incidence of perforation in the case of gastric cancer was $0.74 \%$ of all gastric cancer patients. All the patients were diagnosed by pathological examination of the resected specimen or biopsy specimen. The KaplanMeier survival curve in patients with free perforation due to gastric cancer is shown in Fig. 2. The median survival time of patients with perforated gastric cancer was 195 days after surgery. We compared the clinicopathologic characteristics between patients with $\mathrm{T} 3$ tumors (classified according to the depth of tumor invasion) with free perforation and those without free perforation (Table III). There was no difference between the groups in terms of age, gender, location of the tumor, histology, nodal involvement, venous invasion and lymphatic invasion. The maximal tumor size in patients with gastric cancer perforation was significantly greater than that in patients without perforation. Patients with perforation had a significantly poorer overall survival rate than those who had T3 depth of tumor without perforation (Fig. 3). In addition, in patients with perforation, recurrence of peritoneum occurred more frequently, but the data did not indicate statistical significance (Table IV).

\section{Discussion}

In this study, we showed that intraoperative findings could not be used to accurately diagnose the cause of gastric perforation, since the sensitivity of these findings was only $50 \%$. In addition, patients with gastric cancer perforation had a poorer overall survival rate than those who had $\mathrm{T} 3$ tumors without perforation; this is consistent with the reports of previous studies $(2,4,6,7)$.

Perforation of gastric cancer results in an acute abdominal syndrome due to leakage of gastric contents and the consequent peritonitis. Although it has been reported that approximately $10-16 \%$ of all gastric perforations are caused by gastric cancer $(7,8)$, malignancy is frequently diagnosed only on the basis of postoperative pathological examination. It is often difficult to recognize the type of lesion that caused gastric perforation at the time of emergency surgery, particularly when pathological evaluation of frozen sections cannot be performed due to 
Table III. Clinicopathological characteristics of patients with perforated gastric cancer and $\mathrm{T} 3$ tumor without a free perforation.

\begin{tabular}{|c|c|c|c|}
\hline & $\begin{array}{c}\text { With } \\
\text { perforation } \\
(n=5)\end{array}$ & $\begin{array}{c}\text { Without } \\
\text { perforation } \\
(n=196)\end{array}$ & P-value \\
\hline Age (years) & $65.2 \pm 7.2$ & $61.8 \pm 0.9$ & 0.55 \\
\hline Gender (M/F) & $2 / 3$ & $118 / 78$ & 0.37 \\
\hline \multicolumn{4}{|l|}{ Tumor location } \\
\hline Upper third & $0 \quad(0.0 \%)$ & $43(21.9 \%)$ & \\
\hline Middle third & $2(40.0 \%)$ & $87(44.4 \%)$ & 0.35 \\
\hline Lower third & $3(60.0 \%)$ & $66(33.7 \%)$ & \\
\hline \multicolumn{4}{|l|}{ Histology } \\
\hline Diffuse & $3(60.0 \%)$ & $134(68.4 \%)$ & 0.68 \\
\hline Intestinal & $2(40.0 \%)$ & $62(31.6 \%)$ & \\
\hline \multicolumn{3}{|l|}{ Nodal involvement } & \\
\hline $\mathrm{pN} 1$ & $5(100.0 \%)$ & $90(45.9 \%)$ & 0.22 \\
\hline $\mathrm{pN} 2,3$ & $0 \quad(0.0 \%)$ & $85(43.4 \%)$ & \\
\hline \multicolumn{4}{|l|}{ Venous invasion } \\
\hline v0, v1 & $4(80.0 \%)$ & $127(64.8 \%)$ & 0.47 \\
\hline $\mathrm{v} 2, \mathrm{v} 3$ & $1(20.0 \%)$ & $69(35.2 \%)$ & \\
\hline \multicolumn{4}{|l|}{ Lymphatic invasion } \\
\hline ly0, ly1 & $0 \quad(0.0 \%)$ & $51(26.0 \%)$ & 0.19 \\
\hline ly2, ly3 & $5(100.0 \%)$ & $145(74.0 \%)$ & \\
\hline $\begin{array}{l}\text { Maximal tumor size } \\
(\mathrm{cm})\end{array}$ & $92.4 \pm 13.3$ & $62.6 \pm 2.4$ & 0.03 \\
\hline
\end{tabular}

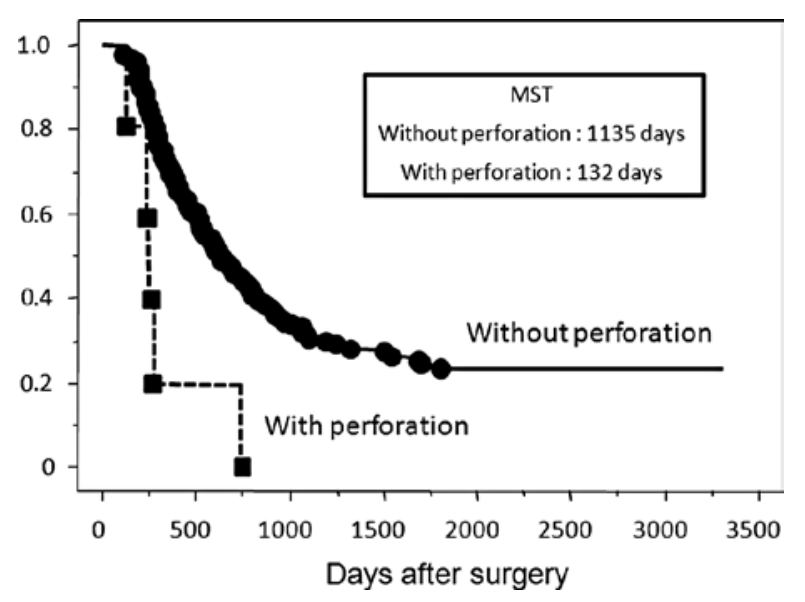

Figure 3. Overall survival rate in patients with gastric cancer of T3 tumor depth. Median survival time is inserted. MST, median survival time. $\mathbf{n}$, gastric cancer patients with a free perforation; $\bullet$, gastric cancer patients who had T3 tumors without a free perforation.

unavailability of the sections (9). Under such conditions, the surgeon should diagnose the cause of perforation on the basis of rigidity of the gastric wall and lymph nodes, size of ulceration and the presence of metastasis in the liver and peritoneum. Moreover, intraoperative endoscopic examination may be useful for identifying the cause of gastric perforation $(1,7,10)$.
Table IV. Recurrence of patients with perforated gastric cancer and $\mathrm{T} 3$ tumor without a free perforation.

\begin{tabular}{llcc}
\hline & $\begin{array}{c}\text { With } \\
\text { perforation } \\
(\mathrm{n}=5)\end{array}$ & $\begin{array}{c}\text { Without } \\
\text { perforation } \\
(\mathrm{n}=196)\end{array}$ & P-value \\
\hline Recurrence & & & \\
Yes & $4(80.0 \%)$ & $75(38.3 \%)$ & 0.50 \\
No & $1(20.0 \%)^{\mathrm{a}}$ & $121(67.7 \%)$ & \\
Site of recurrence & & & \\
Peritoneum & $3(75.0 \%)$ & $28(37.3 \%)$ & 0.49 \\
Locoregional & $1(25.0 \%)$ & $27(36.0 \%)$ & \\
Liver & $0(0.0 \%)$ & $10(13.3 \%)$ & \\
Distant organ & $0(0.0 \%)$ & $6(8.0 \%)$ & \\
Unknown & $0(0.0 \%)$ & $4(5.3 \%)$ & \\
\hline
\end{tabular}

aPatient died of rupture of an abdominal aortic aneurysm on postoperative day 5 .

In this study, the patients with gastric cancer perforation were significantly older than those with gastric ulcer perforation and had greater size of tumor than those with gastric cancer without free perforation.

Lehnert et al proposed 2-stage radical gastrectomy for the treatment of perforated gastric cancer (8); however, this procedure is associated with adhesion and the appropriate time point at which the secondary radical gastrectomy should be conducted has not been determined (5). Thus, the optimal treatment for perforated gastric ulcer or cancer remains debatable. Recently, many studies have reported the use of laparoscopic local repair as the first step of surgery, followed by radical open gastrectomy with appropriate lymphadenectomy 17-20 days after the first-step surgery (11-13). All of the studies emphasized that only slight adhesion was observed in the secondary radical surgery. This surgical strategy may therefore be considered for the treatment of perforated gastric cancer, even though this approach was never chosen in our experience.

Numerous studies have shown that patients with gastric cancer perforation have a poorer overall survival rate after gastrectomy than those without perforation $(2,4,6,7)$. Besides the scattering of cancer cells due to perforation, this difference in survival rates may also be due to inadequate lymphadenectomy, inadequate examination for dissemination, lymph node metastasis during emergency surgery and the potentially advanced stage of the disease. In addition, preoperative examination for metastasis in the lymph nodes and remote organs could not be adequately performed, leading to underestimation of the stage of the cancer.

In conclusion, to improve the survival rate of patients with perforated gastric cancer and to improve the accuracy of intraoperative diagnosis, endoscopic examination and/ or pathological examination of frozen sections should be performed, whenever possible. In particular, malignant perforation should be suspected when the patient is older and the tumor size is greater. Next, a balanced surgical strategy 
must be chosen, i.e., either radical gastrectomy or local treatment should be used according to the severity of sepsis. Laparoscopic local repair as the first step of surgery, followed by radical open gastrectomy with lymphadenectomy may be considered as an appropriate surgical treatment.

\section{References}

1. Cortese AF, Zahn D and Cornell GN: Perforation in gastric malignancy. J Surg Oncol 4: 190-206, 1972.

2. Adachi Y, Mori M, Maehara Y, et al: Surgical results of perforated gastric carcinoma: an analysis of 155 Japanese patients. Am J Gastroenterol 92: 516-518, 1997.

3. Japanese Gastric Cancer; A Japanese Classification of Gastric Carcinoma. 2nd English edition. Gastric Cancer 1: 10-24, 1998.

4. Adachi Y, Aramaki M, Shiraishi N, et al: Long-term survival after perforation of advanced gastric cancer: case report and review of the literature. Gastric Cancer 8: 1; 80-83, 1998.

5. Kasakura Y, Ajani JA, Fujii M, et al: Management of perforated gastric carcinoma: a report of 16 cases and review of world literature. Am Surg 68: 434-440, 2002.

6. Gertsch P, Chow LW, Yuen ST, et al: Long-term survival after gastrectomy for advanced bleeding or perforated gastric carcinoma. Eur J Surg 162: 723-727, 1996.
7. Gertsch P, Yip SK, Chow LW, et al: Free perforation of gastric carcinoma. Results of surgical treatment. Arch Surg 130: 177-181, 1995.

8. Lehnert T, Buhl K, Dueck M, et al: Two-stage radical gastrectomy for perforated gastric cancer. Eur J Surg Oncol 26: 780-784, 2000.

9. Roviello F, Rossi S, Marrelli D, et al: Perforated gastric carcinoma: a report of 10 cases and review of the literature. World J Surg Oncol 4: 19, 2006

10. Jwo SC, Chien RN, Chao TC, et al: Clinicopathological features, surgical management and disease outcome of perforated gastric cancer. J Surg Oncol 91: 219-225, 2005.

11. Hayashi N, Hasuike Y, Fujiwara S, et al: A case of perforated gastric cancer treated with an emergency laparoscopic occlusion followed by radical resection. J Jpn Soc Endosc Surg 12: 61-65, 2007.

11. Kawase H, Ebihara Y, Kitashiro S, et al: A case of gastric perforation of early gastric cancer treated by two-step radical surgery after laparoscopic omentopexy. J Jpn Surg Assoc 66: 2426-2430, 2005.

12. Fukuda N, Wada J, Takahashi S, et al: Perforated gastric carcinoma treated with laparoscopic omental patch repair followed by open radical surgery - report of a case. J Jpn Surg Assoc 66: 2431-2435, 2005. 